\title{
Hoffa's Disease: Retrospective Study of 16 Cases
}

Mohamed Rida El Galiou*, E.Y. Houass, M.Boufettal, R.A. Bassir, M. Kharmaz, M.O. Lamrani, M.S. Berrada

Department of Orthopedics and Traumatology, University Hospital Center of Rabat, Faculty of Medicine and Pharmacy of Rabat, University Mohammed V Souissi, Rabat, 10000, Morocco

DOI: $10.36347 /$ sjams.2020.v08i12.015

| Received: 24.11.2020 | Accepted: 07.12.2020 | Published: 14.12.2020

*Corresponding author: Mohamed Rida El Galiou

\section{Abstract}

Original Research Article

Hoffa's disease was described by Albert Hoffa in 1904, it is rare, benign and unrecognized. Our work corresponds to a retrospective study of 16 cases operated on between 2007 and 2017, correlated with a simple review of the literature. The average age of the patients was 42 years with a predominance of females $(\mathrm{M} / \mathrm{F}=0.6)$. MRI confirmed the diagnosis. The treatment was open surgical and consisted of excision of the mass and resection of the PAH, sometimes associated with surgical procedures. The anatomopathological study of the surgical specimens was systematic in all our patients. Over a mean follow-up of 3 years, the outcome was favorable in $87 \%$ of cases. A recurrence of osteochondroma has been reported and subsequently resumed.

Keywords: Hoffa's fat, knee, patellar syndrome, osteochondroma.

Copyright $\odot$ ( 2020 The Author(s): This is an open-access article distributed under the terms of the Creative Commons Attribution 4.0 International License (CC BY-NC 4.0) which permits unrestricted use, distribution, and reproduction in any medium for non-commercial use provided the original author and source are credited.

\section{INTRODUCTION}

Hoffa's disease or hoffitis is an acute or chronic inflammation of the infra-patellar fat, described for the first time by Albert Hoffa in 1904 [1]. Its pathophysiology is not well understood. However, the traumatic or microtraumatic origin appears to be the most implicated factor in this pathology. The frequent ignorance of this condition by practitioners has motivated us to offer this retrospective analysis of 16 cases with Hoffa's pathology including four cases seen at an advanced stage, with ossification of the Hoffa ligament, we will focus on the etiological aspects. , diagnosis and treatment of Hoffa's pathology correlated with a review of the literature.

\section{Materials ANd Methods}

This is a retrospective study of 16 cases with the pathology of the Hoffa adipose bundle collected between January 2007 and January 2017 in the traumatology and orthopedics department of the Ibn Sina hospital center, Rabat.

The aim of this work is to study their epidemiological; anatomopathological; diagnostic and therapeutic aspects with a review of the literature.

\section{RESULTS}

The ages of our patients ranged from 37-50 years with an average of 42 years. Women represented $62.5 \%$ of cases. The risk factors were dominated by overexertion of the joints: particularly sports and obesity with $50 \%$ and $25 \%$ of cases respectively. The right knee was affected in $75 \%$ of cases. No bilateral impairment was noted. The consultation period varied between 03 months and 05 years. 14 patients presented with mechanical knee pain $(87.5 \%), 6$ patients with patellar syndrome $(37.5 \%), 4$ patients with stiffness in flexion $(25 \%)$ and 10 patients with swelling over the patellar tendon $(62.5 \%$ Clinical examination found hard swelling over the patellar tendon in $37.5 \%$ of patients, renitant swelling in $37.5 \%$ of patients and impasto over the tendon in $12.5 \%$ of patients. All our patients underwent a standard $\mathrm{x}$-ray of the knee, face and profile, objectifying: Ossification of Hoffa's fat in 8 patients $(62.5 \%)$, early osteoarthritis in 4 patients (25\%), chondroma and an osteochodrma in a patient. The X-ray was normal in one patient. The tomodensitometry was performed in 6 of our patients and revealed: a tilt of the patella under the effect of mass of ossifications, a chondroma within the adipose tissue of Hoffa with an oedematous inflammatory range, an osteohondroma in $33 \%$ of patients respectively. MRI was performed in 12 of our patients and revealed a mucoid cyst in 2 of our patients.

All of our patients received medical treatment with analgesics and NSAIDs in the first place and then open surgery. The surgical procedure consisted of: resection of the Hoffa fat bundle in all of our patients; excision of ossifications in $50 \%$ of patients; partial synovectomy, repair of the patellar patellar ligament with release of the external fin according to Ficat, 
resection of the mucoid cyst, resection of the chondroma and resection of the osteochondroma in $12.5 \%$ of patients. The postoperative consequences were simple.

All of our patients benefited from postoperative functional rehabilitation of the operated knee as soon as the pain disappeared. It consisted of strengthening the quadriceps muscle by isometric contractions; knee joint lapping; passive mobilization with Kinétec then active by flexion exercises.

The anatomopathological study of the surgical specimens taken confirmed the diagnosis of Hoffa's pathology in all our patients, osteochondroma in 2 patients, chondroma in 2 patients and villonodular synovitis in 2 other patients.

On an average follow-up of 3 years, the evaluation of our results was carried out according to the criteria of the Cincinnati Knee Rating System (CKRS). The therapeutic results according to the Cincinnati criteria in our patients are as follows: satisfactory results for $62.5 \%$ of the patients, moderately satisfactory results for $25 \%$ of the patients, mediocre results for $12.5 \%$ of the patients.

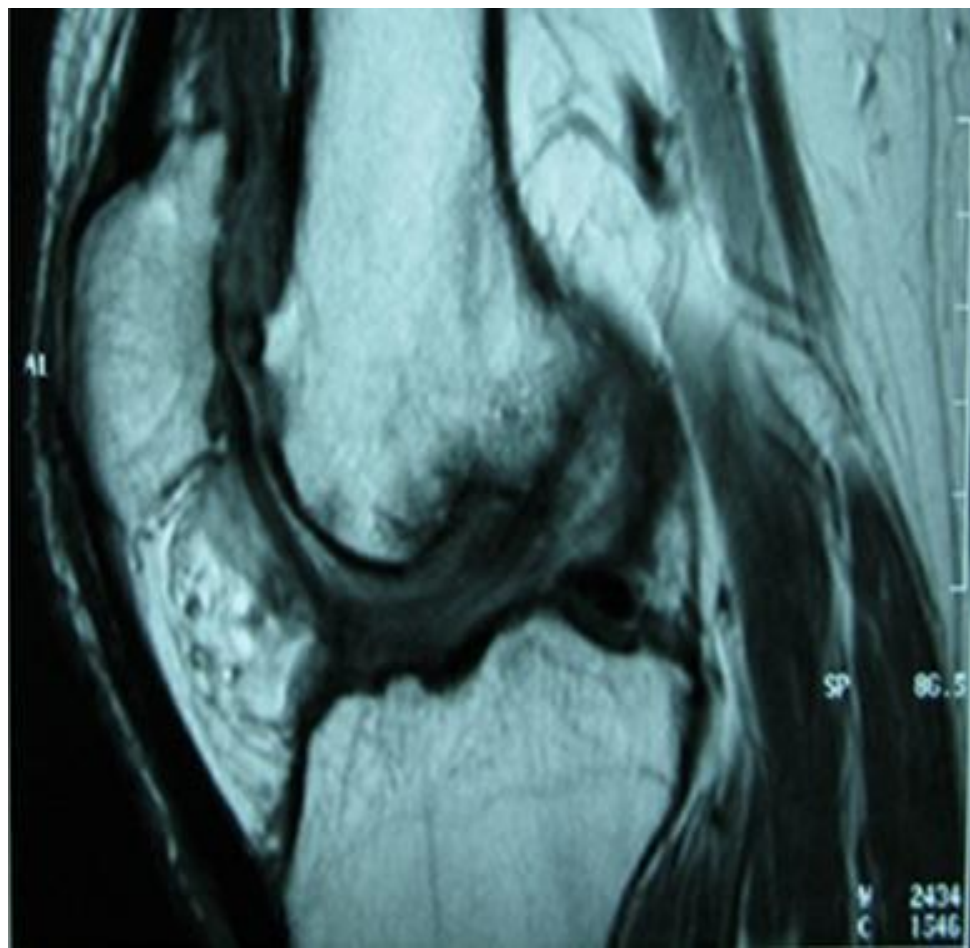

Fig-1: MRI of the knee showing calcification of Hoffa's fat

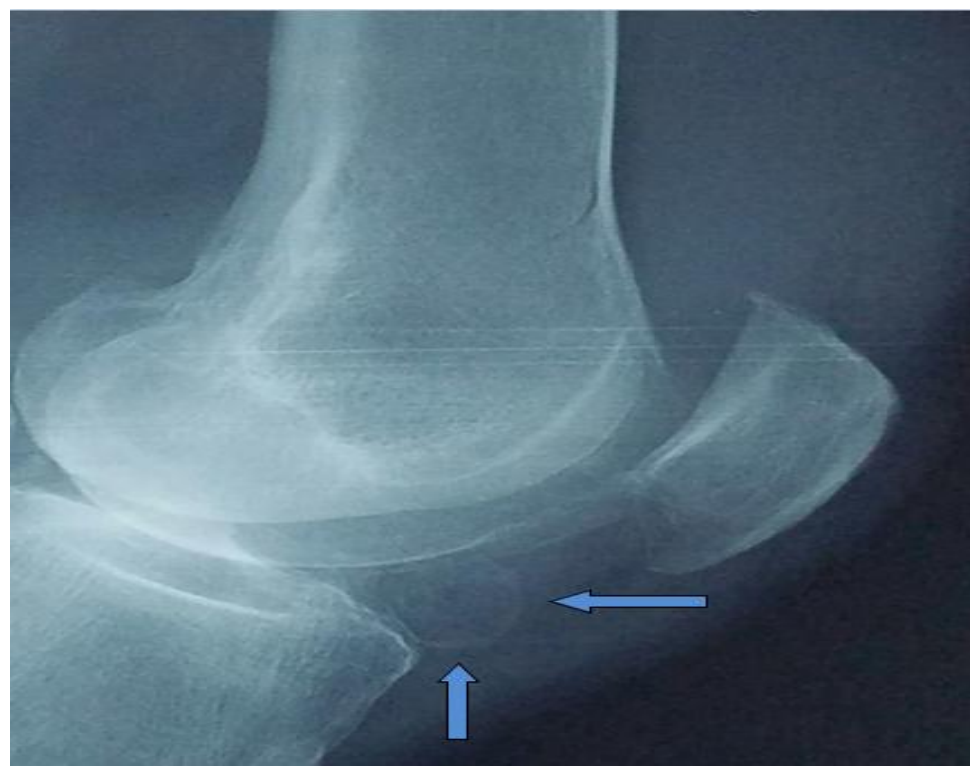

Fig-2: Profile x-ray of the knee showing a chondroma projecting into Hoffa's fat 


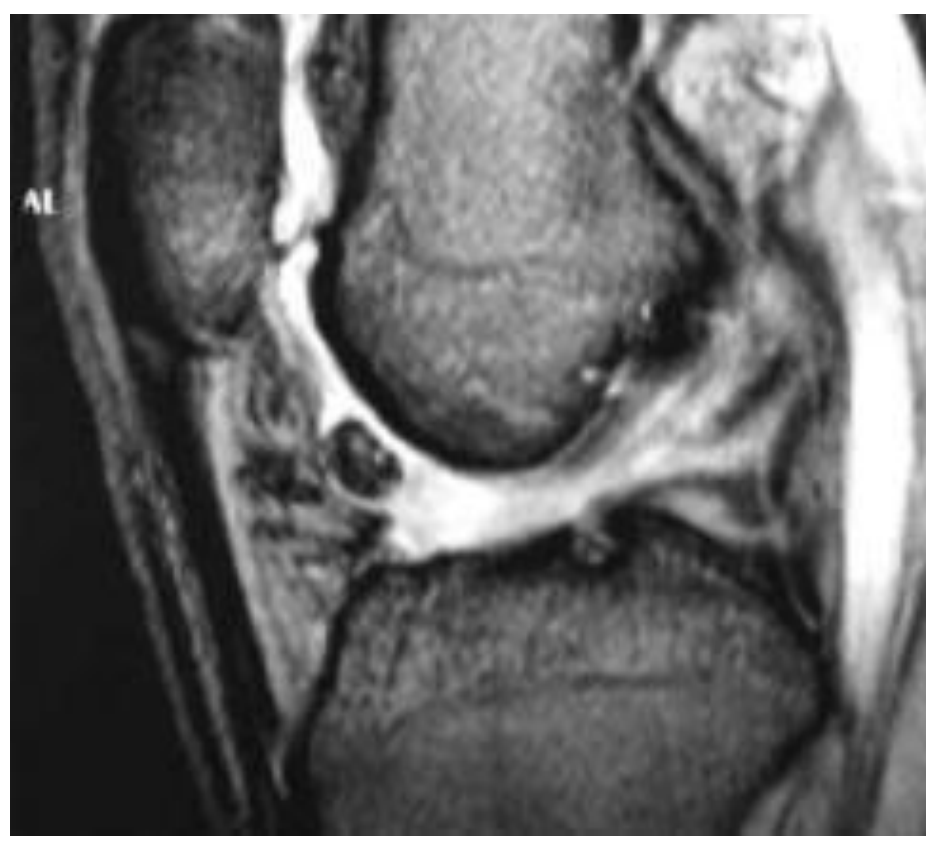

Fig- 3: MRI of the knee showing an osteochondroma at the expense of the Hoffa ligament.

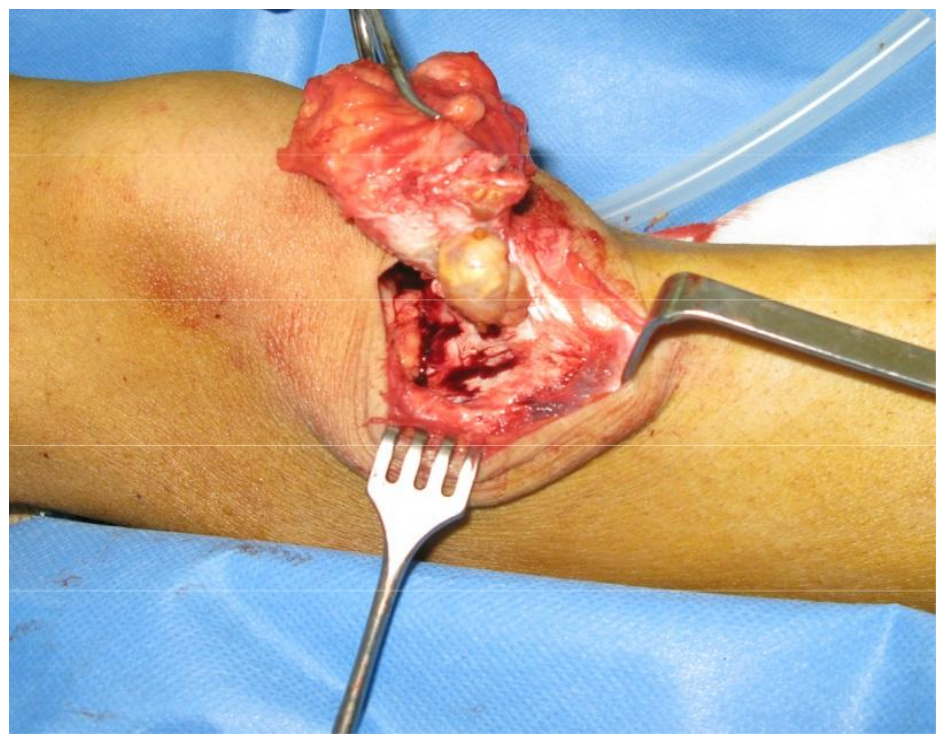

Fig-4: Operative view showing villonodullarysynovitis, developed at the expense of the synovium lining the posterior surface of the patellar tendon

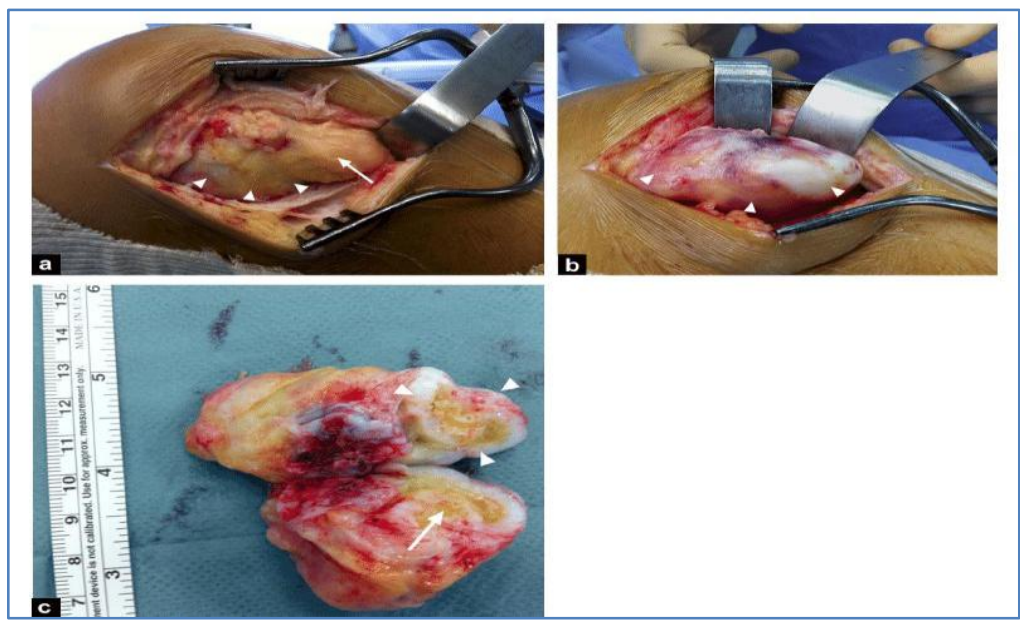

Fig-5: (a-b): Operative view showing Hoffa's fat (arrow) and a large tumor covered with cartilage. (c): The macroscopic appearance is in favor of an osteochondroma with a central bone part covered with cartilage tissue 


\section{DISCUSSION}

The inflammation of the Hoffa is caused by the crushing of the Hoffa fat between the femur and the tibia during extension. Its pathophysiology is not well known. However, several mechanisms are implicated: acute trauma, microtrauma, overuse (repeated hyperextension and rotation). The whole will be responsible for an hypertrophy of the fat causing a vicious circle of hemorrhagic, acute inflammatory and necrotic processes, fibrosing or even chronic ossification [2-4]. In the acute phase, fatty hypertrophy is linked to edema and to hemorrhagic and inflammatory phenomena. In the chronic phase, the inflammatory adipose tissue is transformed into a scarred fibrocartilaginous tissue or even more rarely calcifications of the fat as in the case of our patient. The clinical picture is classic anterior knee pain when going up and down stairs (patellar syndrome) [3,4]. Hoffa's disease affects young womenmore often. The classic symptomatology being anterior knee pain when going up and down stairs (patellar syndrome). The Hoffa test, performed on a patient in the supine position with the hip and knee flexed to $90^{\circ}$, involves causing pain on palpation of the lateral and medial edges of the patellar ligament during knee extension [5]. Three entities can be distinguished from Hoffa's disease: lateral patellofemoral friction syndrome [6], impingement on an infra-patellar plica and arthrofibrosis or "cyclops syndrome". They are not always easy to distinguish, and there is probably an overlap between lateral patellofemoral friction syndrome, infra-patellar plica impingement and Hoffa's disease [7-9]. MRI is the examination of choice for analyzing Hoffa's fat, showing significant edema of the infra-patellar adipose body associated with a fibrous area and sometimes even hemosiderin deposits and calcifications. Radiography is of particular interest during the ossified stages. Radiography is of particular interest during the ossified stages. The differential diagnosis with Hoffa's disease arises mainly with tumoral pathologies (intracapsular chondromas, synovitis, etc.) $[10,11]$.

Conservative treatment will be offered as a first-line treatment based on ice, physiotherapy (strengthening of the quadriceps in particular the vastusmedialis muscle), oral NSAIDs, more or less associated with immobilization. It can also be proposed an infiltration of corticosteroids in the fat of Hoffa [12]. If conservative treatment has failed or if Hoffa's disease has become chronic, arthroscopic resection remains the treatment of choice.

\section{CONCLUSION}

Hoffa's disease is rare without being exceptional. The clinical diagnosis is easy and comes down to anterior knee pain sometimes associated with a palpable mass over the patellar tendon. MRI is the exam of choice for making the diagnosis. Treatment is primarily medical, in case of chronicization and failure of medical treatment, surgical treatment is required.

\section{REFERENCE}

1. Maurel B, Le TC, Cohen M, Acid S, Bierry G, Parratte S, Flecher X, Argenson JN, Petit P, Champsaur P. Infrapatellar fat pad: anterior crossroads of the knee. Journal de radiologie. 2010 Sep;91(9 Pt 1):841-55.

2. Jacobson JA, Lenchik L, Ruhoy MK, Schweitzer ME, Resnick D. MR imaging of the infrapatellar fat pad of Hoffa. Radiographics. 1997 May;17(3):67591.

3. Hoffa A. The influence of the adipose tissue with regard to the pathology of the knee joint. Journal of the American medical Association. 1904 Sep 17;43(12):795-6.

4. Magi M, Branca A, Bucca C, Langerame V. Hoffa disease. Italian journal of orthopaedics and traumatology. 1991 Jun;17(2):211-6.

5. Ruyer A, Cyteval C, Hamoui M, Dallaudiere B, Zarqane H, Viala P, Larbi A. La maladie de Hoffa: à propos de 5 cas. Journal de Radiologie Diagnostique et Interventionnelle. 2014 Nov 1;95(11):1068-73.

6. Barbier-Brion B, Lerais JM, Aubry S, Lepage D, Vidal C, Delabrousse E, Runge M, Kastler B. Magnetic resonance imaging in patellar lateral femoral friction syndrome (PLFFS): prospective case-control study. Diagnostic and interventional imaging. 2012 Mar 1;93(3):171-82.

7. Saddik D, McNally EG, Richardson M. MRI of Hoffa's fat pad. Skeletal radiology. 2004 Aug $1 ; 33(8): 433-44$.

8. Johnson DP, Eastwood DM, Witherow PJ. Symptomatic synovial plicae of the knee. The Journal of bone and joint surgery. American volume. 1993 Oct;75(10):1485-96.

9. Cothran RL, McGuire PM, Helms CA, Major NM, Attarian DE. MR imaging of infrapatellar plica injury. American Journal of Roentgenology. 2003 May;180(5):1443-7.

10. [10]: Sheldon PJ, Forrester DM, Learch TJ. Imaging of intra-articular masses. Radiographics 2005 ; 25: 105-119

11. Helpert C, Davies AM, Evans N, Grimer RJ. Differential diagnosis of tumours and tumour-like lesions of the infrapatellar (Hoffa's) fat pad: pictorial review with an emphasis on MR imaging. European radiology. 2004 Dec 1;14(12):2337-46.

12. Duri ZA, Aichroth PM, Dowd G. The fat pad. Clinical observations. The American journal of knee surgery. 1996;9(2):55. 